\title{
Taking Time for the Environment: On Timing and the Role of Delays in Environmental and Resource Economics
}

\author{
Lucas Bretschger $^{1}$. Sjak Smulders ${ }^{2}$
}

Published online: 22 August 2017

(C) Springer Science+Business Media B.V. 2017

\begin{abstract}
Ecosystem transformation and climate change evolve over long time scales. The effects of the economic decisions on the natural environment are also of a long-run character because they relate to investment decisions and capital stocks. At the same time, the economy is short-sighted and subject to different kinds of market failures. The time it takes to notice the changes and adequately address the associated problems affects the dynamics and inertia of the process. We discuss some recent contributions and new research questions that deal with time and timing in environmental and resource economics.
\end{abstract}

Keywords Time $\cdot$ Inertia $\cdot$ Environmental policy $\cdot$ Climate change $\cdot$ Decision delay

JEL Classification Q20 - Q32 · Q54

\section{Time in Economics}

Time plays an important role in environmental and resource economics. Ecological systems experience significant dynamics while changes in the natural environment may affect the economy with major time delays. The depletion of non-renewable resources and the accumulation of pollution stocks create a direct link between the present and the future, i.e. the current state of the economy and its future capacity. Every ton of carbon emitted today will have a long-lasting impact on future climate conditions and every ton of raw material extracted from the ground will not be available in the future if not fully recycled. Investments

Sjak Smulders

j.a.smulders@uvt.nl

Lucas Bretschger

lbretschger@ethz.ch

1 CER-ETH Centre of Economic Research at ETH Zurich, ZUE F7, CH-8092 Zurich, Switzerland

2 Department of Economics, CentER, and TSC, Tilburg University, PO Box 90153, 5000 LE Tilburg, The Netherlands 
in energy-intensive sectors like buildings, infrastructure, and transportation have an inherent long-run character so that current decisions affect the ecology and the economy over a very long period. Time is also crucial when applying cost-benefit analysis which requires using intertemporal discount rates. Finally, time is the central issue for all reflections on intergenerational equity which are increasingly important with global pollution problems such as climate change.

Classical economics integrated nature into the theory by using the factor land, but did not particularly highlight the importance of time. The focus on the static or "natural" price precluded a separate analysis of transition periods and long-run dynamics. It was one of the great achievements of Böhm-Bawerk (1884) to assign the complex issue of time its place in the theory. He explained the rationale of positive interest rates by explicitly distinguishing consumption goods and capital inputs according to different points in time. The new concept of capital induced the notion of time preferences, which in turn led to the concept of time-discounting in modern macroeconomics and climate studies. The seminal contribution of Hotelling (1931) on exhaustible resource use documents that resource economists were among the pioneers exploring the long-run dynamics of the economy. In various other areas of environmental economics the time dimension has played a central role in modeling since then. Prominently, exploring the long-run interlinkages between the economy and the climate system requires assigning time a prominent place in modeling.

The question of how to introduce specific aspects of time and timing into the theory has fostered continual reflections in many areas of economics; for an early informal survey see Rosenstein-Rodan (1934). Some specific aspects of time are worth mentioning. Remarkably, the constraint of time is the same for all individuals, governments, and firms irrespective of all other conditions. Notwithstanding, individuals' focus, longevity and preferences may differ markedly, which may lead to considerable friction and externalities between these groups. Moreover, time can neither be stored nor accumulated. However, when other goods are stored and accumulated, it is exactly time which mainly determines the value of these activities. It is true that all economic activities take time but that in many theories this aspect of reality is entirely disregarded. This is not a deficiency in general as the need for complexity reduction in economic models is large. The requirement of mathematical formalization often limits the numbers of aspects which can be included in a model while providing the clear benefit of consistent theory-building.

\section{Time and the Environment}

In environmental economics, all problems that are not closely intertwined with resource stocks, capital stocks, or pollution stocks may be analyzed in an a-temporal framework. For example, an optimal policy design for a flow-pollution problem may be analytically derived abstracting from time. However, the more capital investment decisions are involved, the larger becomes the need to include intertemporal aspects into the theory. Often there is a public concern that environmental policies harm the growth process, which economic analysis can only address when including an endogenous growth mechanism into a model. Similarly, as soon as resource stock depletion and pollution stock accumulation play a role for an environmental issue, time and the timing of decisions have to be considered. Things become even more complex when ecosystems react with time delays and/or in a nonlinear way on anthropocentric impacts. Finally, many private and public decisions include cost and benefits in the future so that the comparison of different points in time becomes central. The problem is significantly accentuated when future generations are not necessarily richer than 
current generations, an assumption which has framed the mindset of many researchers in the past. With the predicted effects of climate change underlying conditions have potentially changed, however, at least for the climate vulnerable regions of the world.

Time is not only an issue for theories on optimal market decisions and best policy responses but also a challenge for policy making under real-world conditions. Environmental policies often suffer from a relatively low ranking on the political agenda because their costs are highly visible and appear in the present while the benefits are widely spread and may only be effective in the future. It is a well-known preference of policy makers to concentrate on policies with an immediate impact and to delay decisions on long-run issues like the transition to a green economy. This is even more likely when environmental problems are of a global nature so that delaying own policies and free-riding on others' efforts become a tempting option. Accordingly, not only the imperfections of the markets but also those of the political decision process have to be considered in environmental economics. By appropriately taking into account the time aspect in environmental modelling, impact analysis and policy evaluation, researchers can provide guidelines and benchmarks for an efficient political process. By analyzing the effects of optimal policies, deficient policies, and missing policies on the welfare of future generations, economists can contribute to an equitable treatment of future generations. This set of broad and deep questions offers a large variety of opportunities for further research in environmental and resource economics.

\section{New Research}

Studying the role of time for environmental and resource economics, this special issue covers three major areas of interest. The research was first presented at the Conference on Sustainable Resource Use and Economic Dynamics (SURED) and through the Journal's refereeing and revision process finally selected for publication.

The first section deals with exhaustible resource extraction and stock pollution in the form of climate change. Gaudet and Salant (2017) present in their paper entitled "Modeling Nonrenewable Resources Use with Multiple Demands and Multiple Sources" a generalization of the standard Hotelling model of nonrenewable resource extraction. No economic model has time so prominently as the Hotelling model, since it shows that in the classical setting the interesting question is not how much is extracted (the total stock will be extracted in the end) but at which point in time it is extracted. Extraction at one point in time restricts extraction at other points in time, a scarcity rent emerges, and resource owners arbitrage away differences in profits from extracting today versus extracting tomorrow. Herfindahl (1967) considered a situation with multiple scarce resources (e.g. different grades of oil, or oil vs coal) and derived as a simple timing rule that owners extract resources with lower extraction cost before those with higher costs. Gaudet and Salant (2017) generalize the Herfindahl rule and find that with multiple heterogeneous users and multiple resources, there can be simultaneous use of different resources while switching between resources may occur at different points in time for different users. The Herfindahl result survives in the following sense. If resource $A$ is used before resource $B$ by user $i$, then the extraction cost (including conversion costs and all relevant static costs of lifting and using the resource) of $A$ must be lower than $B$ for this user, and any other user $j$ will not use the resources in reverse order ( $B$ before $A$ ).

The implications of the paper are important. It can explain, for example, why oil from different locations physically is a (fairly) homogeneous product, but economically looks more like a differentiated good due to transport costs, differences in conversion costs and regulation (as empirically documented by Curuk and Sen 2015). It can also explain how 
pollution costs associated with extraction add to extraction costs and determine the optimal order of extraction. Pollution costs differ across users and locations due to local pollution and income effects, so that regions might switch to cleaner resources at different points in time. Accordingly, the transition to alternative energy might be subject to more "delays" in certain regions.

The contribution by Bretschger and Karydas (2017) on "Optimum Growth and Carbon Policies with Lags in the Climate System" uses the Hotelling model to study the interaction between climate change and economic growth. Climate change affects the timing of resource extraction in two ways. First, the damage from climate change reduces productivity and the return to capital, so that changes in the macro-economic interest rate affect the extraction path. In the model by Bretschger and Karydas, climate damage makes it more difficult to accumulate physical capital and the interest rate falls with pollution. This makes consumers less willing to save and postpone consumption, so that the growth rate of consumption falls over time. In the long run, two possibilities may arise. When carbon decays in the atmosphere, the climate problem vanishes as both the stock of fossil resources and the stock of carbon concentrations are depleted. When carbon does not decay, a permanently high carbon stock hurts the endogenous long-run growth rate. Second, climate change calls for policies. A carbon tax delays extraction, which is good for the environment since the carbon stock cumulates less fast; and it is good for growth since more scarce resources are left for future periods. The result is that a carbon tax promotes growth in the short run.

The effects crucially depend on how fast the climate system responds to greenhouse gas emissions. The authors analytically derive the effects on optimal climate policy and economic growth when harmful emission slowly diffuse and later on gradually decay. Slow diffusion thus captures climate inertia. It results in relatively smaller effect of climate change on growth, while at the same time allowing for lower optimal carbon taxes (cf. Lemoine and Rudik 2017). While this seems good news as policy can be less drastic than without climate inertia, policy makers should realize that the optimal carbon tax also grows faster.

The second section includes two contributions on the role of time in the process of delaying environmental policy decisions.

Ott and Soretz (2017) start in their paper "Green Attitude and Economic Growth" from the assumption that households become more aware of environmental problems when their wealth increases or when they suffer increasing damage from pollution. The authors argue that awareness shifts the decision making process. In particular, more environmentally aware agents may see more links between their own actions and environmental problems. Effectively, in the model they internalize a bigger part of the pollution externality, are more willing to mitigate emissions and abate, and bring the economy closer to the social optimum.

The broad implication of this thought experiment is that if the price mechanism does not work because of missing markets, society has to rely on other channels through which the interests of market participants are aligned and information is disseminated. In the Hayekian view, these alternatives are less effective than the price mechanism. When markets are missing, we tend to think of regulation and environmental policies that have to step in. Regulatory and political reality, however, will not easily align all interests and have to deal with their own information problems. The dynamics of consumer action and awareness may support policy changes or at least complement them. The only problem is that such dynamics creates substantial inertia as compared to the ideal world with instantaneous complete market adjustments: the efficient actions and right policies take time to materialize since awareness arises only over time when wealth has sufficiently grown, and awareness has incorporated the changed reality of pollution problems. A question remaining is if this behavioral change will 
be sufficiently fast and significant in practice. Maybe insights from behavioral economics and experiments may further quantify this mechanism.

In his paper "Moving toward Greener Societies: Moral Motivation and Green Behaviour", Cerda Planas (2017) argues that moral principles can induce people to internalize pollution problems. In particular, if private agents feel responsible for doing the morally right thing, they may take decisions partly based on what would happen if everybody else acted in the same way they do. Such a "Kantian morale" effectively results in internalizing damages from pollution. It contrasts with a "Homo Economicus morale" by which only private benefits and costs enter the decision. Cerda Planas (2017) allows both morales to play a role for individual decisions. When marginal damages increase with pollution stock, the harm from emissions becomes bigger over time and the Kantian driver becomes stronger in individual decisions. Thus over time, and only with a delay, pollution problems gradually become more internalized, similar to the result in Ott and Soretz (2017). Environmental policies can try to cope with this inertia and allude to moral motivations. In Cerda's model, consumers have a binary choice between consuming a clean good or consuming a polluting good. The former is the good thing to do according to the Kantian morale, but the latter brings larger private benefits for the Homo Economicus. Agents differ with respect to the weight they put on both considerations. A subsidy to the clean good is a policy option that can make agents switch from polluting to clean consumption. Cerda adds in his model peer pressure and political dynamics to analyze how over time the share of green consumers can change. He identifies cases of lock in and cases in which a cascade of actions towards green behavior arises. The paper shows that it is fruitful to think of delayed action in environmental policy as the result of a combination of ethical, behavourial, and socio-political factors.

A third aspect of timing is the use of environmental policy during different phases of the business cycle. In the paper by Van den Bijgaart and Smulders (2017) entitled "Does a recession call for less stringent environmental policy? A partial-equilibrium second-best analysis" the focus is on investment in clean technologies by heterogeneous firms. Environmental taxes would make firms internalize the pollution externality but do not result in green investments by those firms that are credit constrained, which might happen during recessions in particular. Furthermore, firms might not invest when hit by negative productivity or demand shocks because of an economy-wide recession. Business cycle dynamics and market frictions affect the timing of pollution and delay environmentally motivated investment. The question arises how policy should respond. The paper argues that under mildly restrictive assumptions on functional forms, the optimal response to a (persistent) negative productivity shock or a tightening of credit is to reduce the emission tax.

The papers in the special issue all contribute to the economic analysis of time and its links to the identification of effective environmental policies. We hope they will forcefully inspire future research and actual policies towards a sustainable economic future.

\section{References}

Böhm-Bawerk E (1884) Kapital und Kapitalzins. Wagner, Innsbruck

Bretschger L, Karydas C (2017) Optimum growth and carbon policies with lags in the climate system. Environ Resour Econ . doi:10.1007/s10640-017-0153-4

Cerda Planas L (2017) Moving toward greener societies: moral motivation and green behaviour. Environ Resour Econ. doi:10.1007/s10640-017-0167-y

Curuk M, Sen S (2015) Oil trade and climate policy. Cesifo working paper no. 5285

Gaudet G, Salant S (2017) Modeling nonrenewable resources use with multiple demands and multiple sources. Environ Resour Econ. doi:10.1007/s10640-016-0003-9 
Herfindahl OC (1967) Depletion and economic theory. In: Gaffney M (ed) Extractive resources and taxation. University of Wisconsin Press, Madison, pp 63-90

Hotelling H (1931) The economics of exhaustible resources. J Polit Econ 39:137-175

Lemoine D, Rudik I. (2017) Steering the climate system: using inertia to lower the cost of policy. Am Econ Rev (forthcoming)

Ott I, Soretz S (2017) Green attitude and economic growth. Environ Resour Econ. doi:10.1007/s10640-0160061-z

Rosenstein-Rodan PN (1934) The role of time in economic theory. Econ New Ser 1(1):77-97

Van den Bijgaart I, Smulders S (2017) Does a recession call for less stringent environmental policy? A partialequilibrium second-best analysis. Environ Resour Econ. doi:10.1007/s10640-017-0157-0 